\title{
BMJ Global Health Community preferences for a social health insurance benefit package: an exploratory study among the uninsured in Vietnam
}

\author{
Hoa Thi Nguyen, ${ }^{1}$ Tinh Viet Luu, ${ }^{2}$ Gerald Leppert, ${ }^{3}$ Manuela De Allegri ${ }^{1}$
}

To cite: Nguyen HT, Luu TV, Leppert G, et al. Community preferences for a social health insurance benefit package: an exploratory study among the uninsured in Vietnam. BMJ Glob Health 2017;2:e000277. doi:10.1136/ bmjgh-2016-000277

Received 28 December 2016 Accepted 2 June 2017

\section{CrossMark}

- Additional material is published online only. To view please visit the journal online (http://dx.doi.org/10.1136/ bmjgh-2016-000277)

${ }^{1}$ Institute of Public Health, Faculty of Medicine, University of Heidelberg, Heidelberg, Germany

${ }^{2}$ Institute for Social Security

Science, Vietnam Social

Security, Hanoi, Vietnam

${ }^{3}$ German Institute for

Development Evaluation (DEval), Bonn, Germany

Correspondence to

Mrs. Hoa Thi Nguyen; hoa.

nguyen@uni-heidelberg.de

\section{ABSTRACT}

Understanding public preferences in terms of health benefit packages (HBPs) remains limited, yet gathering community insights is an important endeavour when developing people-centred health systems and moving towards universal health coverage. Our study aimed to address this gap in knowledge by eliciting community preferences for the social health insurance benefit package among the uninsured in Vietnam. We adopted a mixed methods approach that included a ranking exercise followed by focus group discussions. We collected quantitative and qualitative data from 174 uninsured people in Bac Giang, a province in northern Vietnam. Study participants were purposively selected from 12 communities and assembled in 14 group sessions that entailed three stages: participants first selected and ranked benefit items individually, then in groups and finally they engaged in a discussion regarding their decisions. The majority of respondents (both as individuals and as groups) preferred an HBP that covers both curative and preventive care, with a strong preference for the inclusion of highcost care, resulting from rare and costly events (inpatient care), as well as frequent and less costly events (drugs, tests and outpatient care). The process of group discussion highlighted how individual choices could be modified in the context of group negotiation. The shift in preferences was motivated by the wish to protect low-income people from catastrophic expenditure while maximising community access to vital yet costly healthcare services. Future research, interventions and policies can built on this initial exploration of preferences to explore how stakeholders can engage communities and support greater public involvement in the development of HBPs in Vietnam and other low-income and middle-income countries.

\section{INTRODUCTION}

Universal health coverage (UHC) is widely promoted as an approach to increase public access to needed healthcare. ${ }^{1}{ }^{2}$ Questions remains, however, as to how to define service coverage, given the goal of improving health and equity ${ }^{3}$ while being responsive to people's needs and expectations. ${ }^{4}$ Many countries have defined the coverage in relation to the establishment of a health benefit package

\section{Key questions}

What is already known about this topic?

- Community preferences are important inputs in public policy-making process.

- Decisions regarding the nature and content of policies regarding health benefit packages (HBPs) are often made in the absence of evidence on public preferences (including in Vietnam).

What are the new findings?

- Communities in northern Vietnam hold strong preferences for the inclusion of high-cost and essential healthcare services in a social health insurance (SHI) benefit package, covering a mixture of curative and preventive care.

- There was a shift in preferences during the group process, and the main reason for the shift is a wish to protect low-income people from incurring catastrophic healthcare expenditures, and to maximise community access to costly yet life-saving healthcare services.

Recommendations for policy

- Inclusion of high-cost care in the benefit package has the potential to maximise consumer utility among low-income uninsured.

- A HBP covering both curative and preventive care may make SHI more desirable to the uninsured in Vietnam

- The mixed methods approach can be employed to elicit both individual and group preferences for a HBP in Vietnam and other low-income and middleincome countries.

(HBP), which specifies healthcare services be provided using public resources. ${ }^{5}$ It is generally recognised that the selection of these services should be based on cost-effectiveness considerations, balancing against public health and equity concerns. In addition, the design and adjustment of the package should use a transparent, fair and deliberative process that considers evidence and social values in a systematic way. ${ }^{3}$ 
In light of this knowledge, several attempts have been made to understand and include community preferences in the design of a HBP. ${ }^{6-21}$ Few of these studies, however, elicited public preferences for a HBP in low-income and middle-income countries (LMICs). ${ }^{11-13} 17$ Defining an adequate HBP reflecting the needs of the uninsured population has been a major point of concern in public health policy in Vietnam. The country committed to provide UHC to its population and adopted social health insurance (SHI) as the main health financing mechanism towards this aim. ${ }^{22} \mathrm{SHI}$ is compulsory for formal sector workers and voluntary for those in informal sector, with the same benefit package across all groups. In brief, the package covers ambulatory and hospital care, function rehabilitation, screening and early diagnosis of some diseases, transportation in case of referral for certain disadvantaged groups, and a specified list of drugs. ${ }^{22} 23$

At the time when this study was conducted in 2011, nearly $65 \%$ of the Vietnamese were enrolled, ${ }^{24}$ but only $9 \%$ of all insured were voluntarily enrolled..$^{25}$ This indicates extremely low coverage rates among informal sector workers (eg, farmers, near poor and self-employed). ${ }^{25}{ }^{26}$ Addressing the low uptake of insurance among informal sector workers has been recognised as a national priority. ${ }^{27}$ The latest comprehensive review on the Vietnamese health financing system identified the lack of evidence in the formulation and development of the current SHI package as a major obstacle to voluntary enrolment among informal sector workers. ${ }^{28}$

Our study situates itself within this context, by addressing the existing gap in knowledge, that is, understanding community preferences for a HBP among the uninsured in Vietnam. Specifically, our study asked: what are individual and group preferences for a SHI benefit package among the uninsured? And what factors shape and motivate these preferences? Our wish to explore group preferences and not only individual ones like normally done in the economic literature ${ }^{29} 30$ stems from the fact that the SHI programme in Vietnam relies on a single benefit package offered at community-rated premium, ${ }^{22}{ }^{23}$ thus the package has to appeal to the interests of the collectivity while remaining attractive for individuals. Understanding group preferences was also motivated by existing evidence that individual decisions on insurance are shaped by group dynamics. ${ }^{31}$ To address these objectives, we adopted a mixed methods study design including multiple data collection tools, that is, individual survey, ranking exercise and focus group discussions (FGDs). Our relatively complex sequential study design was necessary given our study objectives to examine both individual and group preferences and to understand the reasons behind these preferences.

\section{METHODS}

\section{Study setting}

This study was conducted in Bac Giang, a province in northern Vietnam with a population of 1.6 million individuals (90\% of whom live in rural areas). It comprises nine districts and one provincially run city, which are further distributed in 207 communes, 7 wards and 16 townships. ${ }^{32}$ The province is among the least developed in Vietnam, with literacy and per capita income rates lower than national averages. In 2011, approximately $58 \%$ of the province's residents had SHI coverage. ${ }^{33}$

\section{Sampling}

Two-stage purposive sampling techniques were employed to select the study communities and study participants. Informed by the relevant literature, ${ }^{34}{ }^{35}$ we first selected two rural communes (Tan Dinh and Quang Thinh) and one urban ward (Tran Nguyen Han). We oversampled in rural areas to reflect the predominantly rural make-up of the province. Next, within the rural communes and the urban ward, we consulted local informants and selected 12 communities based on their population size (number of households in each community). Accordingly, the final sample included five small (150-200 households), five medium (200 to fewer than 250 households) and two large-sized communities (over 250 households). Finally, we sampled between 10 and 25 respondents in each community for a total sample of 185 respondents. Given that 11 individuals declined to participate, our final sample comprised 174 respondents. To select respondents, we asked key informants in each commune/ward to indicate individuals with no SHI coverage and who were at least 18 years old. In addition, we asked the key informants to invite only one qualified member per household. We also sought to capture participants who varied by gender, age, income and education by providing the participant selection criteria in the study guideline. When inviting study participants, key informants followed the guideline prepared by the study team, which explained the aim of the study, and the selection criteria and sought verbal consent from the approached individuals.

\section{Data collection: tools and field procedures}

Data collection used quantitative and qualitative tools. We assessed respondents' preferences via a survey, including a specific exercise (conducted at the individual level and then at the group level) to select and rank benefits for the SHI benefit package. The exercise was then followed by a FGD among all who had participated in the survey. Prior to data collection, both quantitative and qualitative data collection tools and procedures were piloted in two additional communities. The first author was in charge of data collection, supported by two local research assistants who the first author trained on questionnaire administration (including modules in ranking activities) and qualitative methods (including a module on note-taking during FGDs).

The quantitative tool consisted of a structured, closeended questionnaire that included a section to assess a person's sociodemographic, economic and health status (see online supplementary file 1), and an exercise to elicit preferences for an HBP. The exercise relied on 
the use of 10 cards. Each card displayed a locally appropriate image to illustrate one of ten possible health services: inpatient care (IP), outpatient care (OP), traditional practitioner care (TP), drugs on prescription (D), preventive care (PC), transportation (TR), laboratory and imaging tests $(\mathrm{T})$, allowance for meals during hospitalisation $(\mathrm{M})$, personal medical equipment (ME) and mental healthcare (MC) (see online supplementary file 2). Mental healthcare was described to include both inpatient and outpatient services for patients with mental disorders and illnesses. Other services were described in detail underneath the corresponding illustration. The study team developed the quantitative tool with reference to the UHC framework, ${ }^{12}$ adapting a prior similar study by one of the authors ${ }^{16}$ and looking at other relevant studies. $^{911} 13$

Since our aim was to gather information on preferences at both the individual and group levels, we administered the survey first individually and later in a group session. Specifically, in each community, we invited all sampled respondents to attend one single collective session. Only in the two large communities, given the high number of sampled respondents, did we hold two of these sessions. This yielded a total of 14 group sessions. Each session included the following steps. First, using a large poster, we introduced the study, explained key terms and obtained written consent from all respondents attending the session. Second, each respondent filled in the sociodemographic section of the questionnaire individually, seeking clarification from a research assistant if needed. Third, individual respondents were asked to engage in the exercise to elicit their preference for the HBP. The research assistants asked respondents to imagine that they would be able to compose their own SHI benefit package to meet their individual preferences. To do this, each respondent was given a set of ten cards, each representing one of ten health services (see above). Respondents were asked to select the five services they would like to see included in the HBP and then to rank them according to their relative priority. A scale of $1-5$ was employed, with a value of 1 attached to the most preferred service and value of 5 to the least preferred. Sufficient space between respondents was left to ensure confidentiality. The arbitrary cut-off point (5 out of 10) was set to force participants to make trade-offs within a given budget and to allow respondents to work with a manageable number of services. Respondents recorded their preferences directly on the corresponding health service cards. Fourth, after selecting and ranking benefits individually, respondents repeated the same exercise in groups. All groups were asked to find a consensus at the end of their discussion and to indicate their preferences on corresponding cards, again using a scale of 1-5. The research team did strictly not interfere with group discussions, but were present at a distance to observe and take notes.

Finally, after the group ranking exercise was completed, respondents were gathered to participate in an FGD, which used a semi-structured guide to explore how and why during the quantitative exercise respondents had moved from an individual towards a collective set of preferences, and the reasons that motivated this preference shift. In addition, respondents were free to raise any additional concerns they had in relation to their group decisions. All FGDs were facilitated by the first author, supported with note-taking by two research assistants in Vietnamese, and were tape-recorded.

\section{Data management}

Data were entered in EpiData V.3.1 software. The quantitative database was then checked for accuracy and consistency. Responses on the selection of benefit types were stored as binary variables, in which we used code ' 1 ' for selected benefits and ' 0 ' for unselected benefits. Ranks were stored as ordered categorical variables with values ranging from 1 to 5 , being obtained directly from the responses. Respondents' individual responses and their corresponding group responses were stored to allow for later matching. Quantitative data were stored anonymously, with no possibility to identify individual respondents.

The first author transcribed verbatim the recording from all FGDs. The transcribed text was left in Vietnamese and stored anonymously. The first author translated into English only the portions of text appearing in this manuscript.

\section{Data analysis}

We analysed quantitative data using the statistical software SPSS V.11.5. Quantitative responses were examined at both individual and group levels. First, descriptive statistics were employed to count selection frequencies for each benefit item. Second, the arithmetic means of the rank scores were computed by attributing a score in accordance to the ranks of the selected and unselected benefits. Specifically, a benefit that was selected and given the first ranking has a score of 1 ; a benefit that was selected and given the second ranking has a score of 2 and so on. We attributed rank 8 to benefits that were not selected and therefore had no rank, as 8 represents the mean of the remaining ranks $(6,7,8,9,10)$.

Third, we examined the composition of the derived benefit packages. In principle, if each participant or group could select 5 benefits out of 10 proposed items, there are up to 252 possible combinations derived from the binomial coefficients of $\left(\begin{array}{l}N \\ n\end{array}\right)$ with $\mathrm{n}=10$ and $\mathrm{n}=5 .{ }^{36} \mathrm{It}$ follows that 174 participants might compose a maximum of 174 different packages through the individual process, and 14 groups might compose a maximum of 14 different packages through the group process. Given the study's focus on collective rather than individual preferences, we examined in detail only the packages selected through group processes and compared them with the packages previously selected by the same individuals in their corresponding group. 
Last, we compared individual and group choices in all three quantitative subanalyses (selections of benefits, rankings of benefits and compositions of the derived packages). In order to carry out the comparison at the individual level, group responses were allocated to each group member and paired with individual response. We used the McNemar test to assess the extent of change with respect to selections of benefit items and compositions of derived benefit packages between the individual and group processes. ${ }^{37}$ For the ranking results, we used the paired samples t-test to examine the changes in the rank scores for benefit items when the study participants switched from their individual decisions to group decisions. Results were appraised as statistically significant if $\mathrm{p}<0.05$.

Qualitative data were analysed using content analysis, which relied on a deductive approach based on the themes and questions addressed in the FGD guide, but still allowed for additional codes to emerge as the reading progressed. ${ }^{38}$ Categories and subcategories were developed, modified and extended on the basis of what themes emerged as the analysis proceeded. Links between categories were identified progressively to illuminate the understanding of the research question. The final interpretation of the findings was discussed among all authors and with the two research assistants, who could refer back to the notes and memos gathered during the data collection process.

\section{RESULTS \\ Study participants}

Between June and July 2011, we conducted 14 collective sessions from the 12 selected communities. Each of these 14 sessions consisted of 8-15 participants for a total of 174 respondents. Sessions lasted 2-2.5 hours. For an outline of respondents' demographic characteristics, see online supplementary file 3 . The majority of respondents were female $(67.2 \%)$, all were literate with $56.9 \%$ having completed at least 6 years of schooling, and $65 \%$ worked in the agricultural sector. The average household monthly income was VND986 $000( \pm 540000)$, equivalent to US $\$ 47( \pm 25)$, which was about US\$6 and US\$19 less than provincial and national averages, respectively. The vast majority of the participants $(87.9 \%)$ stated that at least one of their household members had experienced an illness and sought medical care $(86.2 \%)$ in the prior 12 months. Over a third of all respondents (35.6\%) reported that their households had incurred debt over the past 12 months due to healthcare expenses. Nearly $90 \%$ lived less than $5 \mathrm{~km}$ from the nearest health facility. More than $40 \%$ had at least one household member covered by compulsory SHI, while about $18 \%$ reported at least one household member covered by voluntary SHI.

\section{Quantitative findings}

Selection of benefit types

Table 1 reports the frequency with which individuals and groups selected each benefit item. The table is sorted in descending order of selection frequency. In line with
Table 1 Cumulative individual and group preferences in relation to choice of benefit items $(n=174)$

\begin{tabular}{|c|c|c|c|c|}
\hline \multirow[b]{2}{*}{ Benefit items } & \multicolumn{2}{|c|}{ Individuals } & \multicolumn{2}{|l|}{ Groups } \\
\hline & $\begin{array}{l}\text { Yes } \\
\text { replies }\end{array}$ & $\%$ & $\begin{array}{l}\text { Yes } \\
\text { replies }\end{array}$ & $\%$ \\
\hline Inpatient care & 148 & 85.1 & 14 & 100.0 \\
\hline Preventive care & 144 & 82.8 & 12 & $86.8^{*}$ \\
\hline Drugs on prescription & 123 & 70.7 & 13 & $95.4^{*}$ \\
\hline $\begin{array}{l}\text { Laboratory and imaging } \\
\text { tests }\end{array}$ & 118 & 67.8 & 13 & $93.7^{*}$ \\
\hline Outpatient care & 105 & 60.3 & 9 & 65.5 \\
\hline Meals during hospitalisation & 101 & 58.0 & 6 & 37.9 \\
\hline Transportation & 48 & 27.6 & 2 & 16.1 \\
\hline Traditional practitioner care & 44 & 25.3 & 0 & 0.0 \\
\hline Medical equipment & 23 & 13.2 & 0 & 0.0 \\
\hline Mental healthcare & 16 & 9.2 & 1 & 4.6 \\
\hline
\end{tabular}

*Denotes benefits that recorded the shift in the order of preferences after the group process.

the way in which data were collected, group choices are reported also in relation to the overall number of individuals participating in the groups.

Individuals selected the five most important benefit items in the following order: inpatient care $(85.1 \%)$, preventive care $(82.8 \%)$, drugs on prescription $(70.7 \%)$, laboratory and imaging tests $(67.8 \%)$ and outpatient care $(60.3 \%)$. The two least frequently indicated benefit items were medical equipment $(13.2 \%)$ and mental healthcare $(9.2 \%)$. Groups selected the same five benefit items as the most important, but the order of preferences is slightly different: inpatient care (100\%), drugs (95.4\%), tests $(93.7 \%)$, preventive care $(86.8 \%)$ and outpatient care $(65.5 \%)$. No group included traditional practitioner care and medical equipment in their benefit package.

Table 2 displays the effect of group processes on choices for benefit items. When individual choices were replaced with group choices, two changes were possible: yes-to-no or no-to-yes. Three costly services (inpatient care, drugs and tests) recorded substantially more no-to-yes than yes-to-no changes, with the resulting difference being statistically significant. Preventive care and outpatient care also saw more no-to-yes changes than yes-to-no changes, but the difference was not statistically significant. The yes-to-no changes prevailed in transportation, medical equipment, meals, traditional practitioner care and mental healthcare, with the difference being statistically significant for all items except mental care.

\section{Ranking of benefit types}

Table 3 reports ranking results of the individual and group processes. As explained above, the comparison of the individual and group decision is performed by computing the mean scores of the ranks for selected and unselected benefits. The means of the rank scores range 
Table 2 Effect of group process on choices of benefit items $(n=174)$

\begin{tabular}{lllll}
\hline Benefit items & $\begin{array}{l}\text { No change } \\
\text { (replies) }\end{array}$ & $\begin{array}{l}\text { Yes-to-no } \\
\text { change } \\
\text { (replies) }\end{array}$ & $\begin{array}{l}\text { No-to-yes change } \\
\text { (replies) }\end{array}$ & $\begin{array}{l}\text { Significance of difference between yes- } \\
\text { to-no and no-to-yes replies (p values) }\end{array}$ \\
\hline Inpatient care & 148 & 0 & 26 & 0.000 \\
\hline Preventive care & 143 & 12 & 19 & 0.281 \\
\hline Drugs on prescription & 117 & 7 & 50 & 0.000 \\
\hline Laboratory and imaging tests & 121 & 4 & 49 & 0.000 \\
\hline Outpatient care & 105 & 30 & 39 & 0.336 \\
\hline Meals during hospitalisation & 105 & 52 & 17 & 0.000 \\
\hline Transportation & 122 & 36 & 16 & 0.008 \\
\hline Traditional practitioner care & 130 & 44 & 0 & 0.000 \\
\hline Medical equipment & 151 & 23 & 0 & 0.000 \\
Mental healthcare & 152 & 15 & 7 & 0.134 \\
\hline
\end{tabular}

${ }^{*}$ Tested with the non-parametric McNemar test.

from 1 to 8 , with the lower scores indicating a higher level of desirability.

The ranking exercise at the individual level obtained a rather similar order of preference as reported in table 1 , with only one difference where two benefits (drugs and tests) were exchanged in their order of preferences. In comparison to the individual ranking results, the ranking exercise at the group level resulted in a slightly different order of preferences, with preventive care taking the fourth instead of the second position in the priority order. This different preference order was due to the substantial decrease in the means of rank scores for inpatient care, drugs and tests, when the participants moved from their individual to group decision.

The paired samples t-test results confirmed the effect of the group process on the rankings of benefit types (table 3). The observed decrease of the mean scores for the three benefits (inpatient care, drugs and tests) after the group process is statistically significant and consistent with the changes observed in the no-to-yes analysis displayed in table 2. On the other hand, the group process increased the mean scores for the five less frequently selected benefits (meals, transportation, traditional practitioner care, medical equipment and mental healthcare), and the differences were significant for all these five benefits (table 3 ).

\section{Composition of selected benefit packages}

Table 4 reports the composition of the derived benefit packages. Groups selected a total of 6 out of a potential maximum of 14 benefit packages, which in turn had previously been selected by 53 out of 174 respondents during the individual exercise.

The group process bore an effect on choices for all six packages being selected through the group process (table 5). Similar to the displayed patterns of the group effect on choices for benefit items (table 2), two changes could happen here: yes-to-no or no-to-yes. The no-to-yes changes included those changes from any other benefit packages defined during the individual process to one of the six benefit packages assembled during the group process. Package 1, which was composed of the five most frequently selected benefits (IP, OP, PC, T and D), recorded the most changes ( 77 changes), including 68 no-to-yes changes and only 9 yes-to-no changes. Statistically significant differences were observed for packages $1,2,4$ and 6.

\section{Qualitative findings}

Qualitative findings shed light on the process used by groups to reconcile multiple individual preferences and to reach consensus on which services should be included in their preferred benefit package. Thirteen of the 14 groups reached consensus after a collective discussion and analysis process. Only one group opted to vote to select the five preferred benefit items. No group reported that the decision had simply been made by an influential group member, such as an elderly or a powerful person. Respondents reported a general ease in switching opinion in the light of the issues raised during group discussions.

\footnotetext{
"We discussed and analysed to see which services are needed more and have better use." (FGD. 4, rural)

"After the discussion in group, I found that the group choices fit everyone's needs, that is why I changed my opinion and agreed with the group choices." (FGD. 10, urban)
}

Across the groups, discussion was initiated by a description of each benefit item to identify the most needed services. Respondents reported that attention was given to services likely to benefit the wider community rather than individuals, although benefit items were appraised in the light of individual experiences with seeking care. Groups uniformly privileged those services considered to be more costly for inclusion in the HBP as those that people considered vital for their survival, but struggled most to afford in the absence of health insurance. For instance, this reasoning was used to explain the inclusion of inpatient care in the benefit package. 


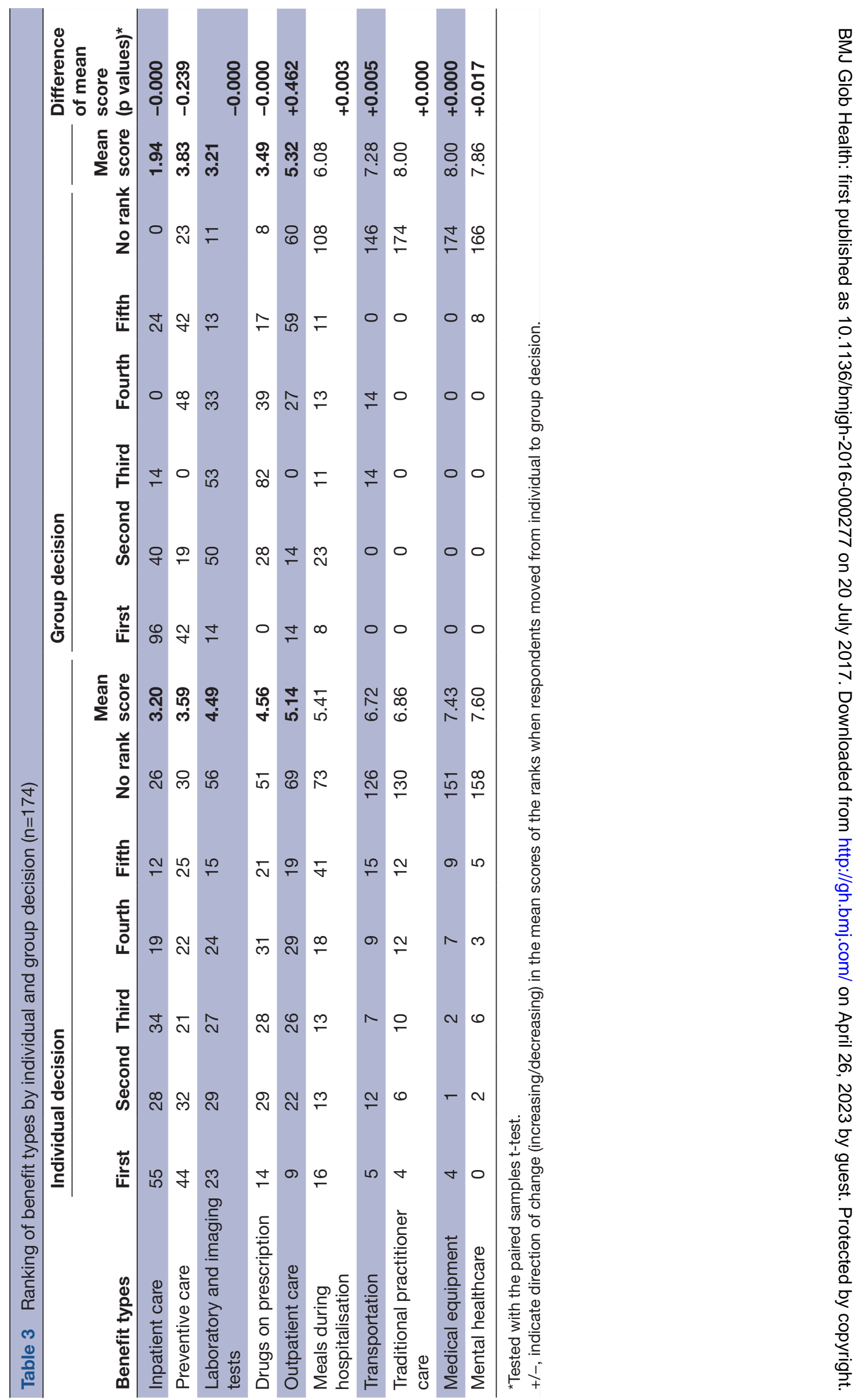


Table 4 Compositions of benefits packages chosen by groups and individuals $(n=174)$

\begin{tabular}{llccc}
\hline Package & Package composition & Groups (n) & Group members (n) & Individuals (n) \\
\hline 1 & IP + OP + PC + T + D & 6 & 80 & 21 \\
2 & IP + PC + T + D + TR & 2 & 28 & 8 \\
3 & IP + PC + T + D + M & 2 & 24 & 12 \\
4 & IP + OP + T + D + M & 2 & 23 & 5 \\
5 & IP + OP + PC + D + M & 1 & 11 & 6 \\
6 & IP + PC + MC + T + M & 1 & 8 & 1 \\
Other packages & n/a & 0 & 0 & 121 \\
& Total & 14 & 174 & 174
\end{tabular}

$\mathrm{D}$, drugs on prescription; IP, inpatient care; M, meals; MC, mental healthcare; OP, outpatient care; PC, preventive care; T, laboratory and imaging tests; TR, transportation.

“...we analysed the services. Some members who have been hospitalized know which services cost more money, then we selected more costly services." (FGD. 3, rural)

".... Coverage of in-patient care is vital especially for people with low income. That is why we all agreed to include this benefit."

(FGD. 4, rural)

Following similar reasoning, respondents expressed their strong preferences for the inclusion of prescription drugs and laboratory and imaging tests. Their explanations stressed the cost associated with these two benefits and their vital role in treatment.

"Drugs are definitely needed for every disease...If there are no drugs, diseases cannot be cured." (FGD. 11, urban)

"Good doctors must still rely on technology. Without tests, good doctors cannot identify the disease. Only when the correct disease is identified, then it can be cured." (FGD. 9, rural)

Second to costly and life-saving services, groups consistently indicated the need to prioritise preventive care. This was explained in relation to poor people's inability to identify and act against health problems autonomously and to the preventive value of routine check-ups and vaccination for the early diagnosis and effective treatment of disease. Preventive care was also perceived as a means of avoiding later healthcare costs.

"Lay people do not have health care knowledge. They need regular medical check-ups to detect diseases in good time." (FGD. 4, rural)
"Regular check-ups and vaccinations are important. If we prevent diseases well, we do not have to spend more money later on." (FGD. 14, urban)

Respondents justified their decision to include outpatient care in the HBP in relation to its frequent use by the wider community. Respondents further defined the value of outpatient care in relation to its ability to detect non-symptomatic conditions and to avoid later hospitalisations.

"Outpatient care is frequently used by our people, as we can treat our illnesses and also find other diseases through outpatient care. We should not wait until being hospitalized, then seeking for medical care." (FGD. 11, urban)

Although they could not include them in the selected package given the constraint to select only five benefit items (the arbitrary limit set to facilitate the tradeoffs), many respondents insisted on the importance of including a meal allowance during hospitalisation and transportation in case of referral. Respondents argued for the inclusion of these additional services, given that their incurred cost could be catastrophic. Similar arguments were raised to motivate the inclusion of mental healthcare, medical equipment and traditional practitioner care. Respondents clearly valued them, but not enough to include them among their preferred five benefits.

Table 5 Effect of group process on choices of benefits packages $(n=174)$

\begin{tabular}{lccll}
\hline Package & $\begin{array}{l}\text { No change } \\
\text { (replies) }\end{array}$ & $\begin{array}{l}\text { Yes-to-no change } \\
\text { (replies) }\end{array}$ & $\begin{array}{l}\text { No-to-yes change } \\
\text { (replies) }\end{array}$ & $\begin{array}{l}\text { Significance of the difference between yes-to-no and } \\
\text { no-to-yes replies (p values)* }\end{array}$ \\
\hline 1 & 97 & 9 & 68 & 0.000 \\
\hline 2 & 144 & 5 & 25 & 0.001 \\
\hline 3 & 142 & 10 & 22 & 0.520 \\
\hline 4 & 152 & 2 & 20 & 0.000 \\
\hline 5 & 161 & 4 & 9 & 0.267 \\
6 & 165 & 1 & 8 & 0.039 \\
\hline
\end{tabular}

*Tested with non-parametric McNemar test. 


\section{DISCUSSION}

This study is among few studies exploring community-stated preferences for a HBP in LMICs, ${ }^{11-13} 17$ and it is the first to be conducted in Vietnam. This study provides a valuable foundation on which to build academic understandings of what services currently uninsured and relatively poor communities in Vietnam wish to see included in their HBP. Without aiming at generalisability at the national level, this study clearly indicates that communities have clear preferences and know what they wish to have from the healthcare system to which they are called to contribute. The value of the study lies in the application of a mixed methods approach, which has allowed us to quantify as well as explain community preferences.

The first finding of relevance is the fact that communities (at the individual and group levels) clearly identified high-cost services resulting from both costly services used on rare occasions (inpatient care) and less costly services used on a frequent basis (drugs, tests and outpatient care) as being the services of primary attention when considering inclusion in an HBP. The public preferences for high-cost services were also reported in similar studies in Burkina Faso ${ }^{12}$ and in rural India. ${ }^{11}{ }^{13}$ The observed preference to include high-cost care (both high unit-cost low-probability and low unit-cost high-probability events) is an indication of rational behaviour, ${ }^{39}$ well aligned with theoretical paradigms postulating that risk-averse individuals are inclined to buy insurance to protect themselves from potentially catastrophic risks. ${ }^{40-42}$ Such a rational choice is relevant in our study context where more than $35 \%$ respondents reported having borrowed money to pay for healthcare costs in the past 12 months and where household out-of-pocket payments still represent about $50 \%$ of total health expenditure. ${ }^{43}$

Equally interesting is the fact that the uninsured mostly farmers and informal economy workers with both low income and low education - valued preventive care, defined as routine check-ups and vaccinations, as much as they valued costly healthcare services. This is a surprising result, especially in a country poor in resources like Vietnam, where the spending on curative care currently accounts for approximately $70 \%$ of the total health expenditure. ${ }^{44}$ In line with the overall configuration of the healthcare system, much of the current benefit package and its associated reimbursement are centred around higher level care. ${ }^{45}$ This focus on higher level care, combined with large disparities in service quality and availability of qualified staff across levels of care, has escalated chronic overcrowding in tertiary facilities, while leaving the first-level providers largely underutilised. ${ }^{25} 26$ This finding provides a clear indication of the misalignment between current patterns of public healthcare spending and actual public preferences. Appraising this finding against the health system performance analytical framework proposed by the $\mathrm{WHO},{ }^{46} 47$ it openly questions the current SHI benefit package and suggests that the Vietnamese healthcare system is not yet responsive to population preferences. Moreover, in explaining the priority placed on preventive care, our qualitative data were consistent with previous evidence from India ${ }^{11} 13$ and clearly indicated that poor communities know the value of preventive care and appreciate its role in maintaining a healthy life.

In line with what was observed in a prior study in India, ${ }^{11}$ our study detected a remarkable effect of the group process on individual preferences. In particular, we found that group processes produced a significant effect on three vital and costly curative services (inpatient care, drugs and tests), where we recorded the highest number of no-to-yes shifts and the most substantial decrease in the means of the rank score. In the process of finding a group consensus, respondents opted for the inclusion of services that are most likely to prevent catastrophic health expenditures for themselves as well as their group members. This finding is interesting and suggests that the group decision-making process can harness the linkage between individual economic motive and the collective social responsibility, indicating that group choices can enhance social welfare. ${ }^{31}$ Our FGDs supported this evidence, as individuals explicitly discussed how they modified their initial choices to respond to the needs of the entire group: "I found that the group choices fit everyone's needs, that is why I changed my opinion and agreed with the group choices."

The non-inclusion of mental health services either at the individual or group level deserves special attention. The low priority attributed to this service was clearly motivated by the respondents who during the FGDs referred to the complexity of the treatment and the perceived uncertainty on its effectiveness as reasons for the non-inclusion. Although there was no statement suggesting that mental patients were subject of discrimination, we cannot exclude that perceptions on the inadequacy of treatment actually stem from such beliefs or whether it was due to inadequate understanding of the respondents on the matter. Further research is needed to enlighten in this regard.

\section{Methodological considerations}

One should consider our findings against the limitation that we conducted the study on a rather small sample drawn in only one province of Vietnam, while the country has in total 64 provinces with diverse socioeconomic, cultural and geographical backgrounds. While ranking exercises are routinely conducted with even smaller sample sizes, ${ }^{734} 48$ we caution against interpreting our findings as generalisable, although we trust that some lessons can be drawn for other LMICs as well, when considering the concept of transferability instead of generalisability. Further, our tool for HBP design provided a simple method for benefit ranking and thus enabled the participation of the community members with different education levels; however, it did not allow any trade-offs beyond the five selected benefit items, and 
thus we could not examine other important attributes of a HBP like co-payment and choice of provider.

Also, we need to be self-reflective on the fact that several elements external to the study could have influenced the shift between individual and group preferences. Although respondents confirmed that their preferences changed as a result of group dialogues (and we did not observe any case in which group decision was shaped by a dominating opinion), we cannot exclude the possibility that respondents might have provided socially acceptable answers to please others. Time might have also influenced their shift, since time elapsed between the two choice elicitation processes, giving respondents more time to form their opinion. In addition, as other research on preferences, we need to acknowledge the potential for status quo bias to have influenced the results. Status quo bias refers to the fact that individuals are always more likely to select in line with what they know and experience. This may explain why the services selected largely corresponded with what available HBPs normally offer. ${ }^{49}$ Likewise, this bias may explain why respondents did not include coverage for mental healthcare, given that they may have limited exposure and experience with these conditions.

\section{CONCLUSION AND POLICY IMPLICATIONS}

On the road to UHC, defining an appropriate HBP to be financed by public resources remains a primary concern in Vietnam and other LMICs. Our study found that the uninsured wished to have the coverage for both curative and preventive care and placed strong preference to include high-cost care. The stated preferences suggest the inclusion of high-cost care has a potential to maximise consumer utility, although we also recognise that providing a mix of curative and preventive care in HBP may make SHI more attractive to the low-income uninsured in Vietnam. In addition, we found a shift in preferences during the group process, confirming the need for eliciting both individual and group preferences when designing a HBP. The mixed methods approach proves to be valuable to gain in-depth understanding of preferences, suggesting its potential application in eliciting public preferences for the development of a people-centred HBP in Vietnam and other LMICs.

\begin{abstract}
Acknowledgements We would like to thank Professor Andreas Ruppel, former director of the Teaching Unit of the Heidelberg Public Health Institute, for the overall guidance and support during the course of thesis preparation. We give our equal thanks to Nguyen Thi Lan and An Thu Huong, the two research assistants who made untiring and generous efforts in supporting the field data collection. Our special thanks go to all study participants, who dedicated their time to join the study. We acknowledge the financial support of the Deutsche Forschungsgemeinschaft and Ruprecht-Karls-Universität Heidelberg within the funding programme Open Access Publishing.
\end{abstract}

Contributors HTN and MDA conceived and designed the study. HTN, TVL and GL developed the data collection tools. HTN and TVL conducted the data collection and prepared the data set. HTN and TVL analysed the data. HTN drafted the manuscript. MDA reviewed, edited and revised the draft manuscripts. All authors interpreted data and revised the manuscript critically. All the authors read and approved the final version of the manuscript.
Funding This study was completed as a requirement for the master's thesis of the first author, who gratefully acknowledges a scholarship from the German Academic Exchange Service (DAAD).

Competing interests None declared.

Ethics approval Institute for Social Security Science of the National Social Security Agency in Vietnam.

Provenance and peer review Not commissioned; externally peer reviewed.

Data sharing statement No additional data are available.

Open Access This is an Open Access article distributed in accordance with the Creative Commons Attribution Non Commercial (CC BY-NC 4.0) license, which permits others to distribute, remix, adapt, build upon this work non-commercially, and license their derivative works on different terms, provided the original work is properly cited and the use is non-commercial. See: http://creativecommons.org/ licenses/by-nc/4.0/

(c) Article author(s) (or their employer(s) unless otherwise stated in the text of the article) 2017. All rights reserved. No commercial use is permitted unless otherwise expressly granted.

\section{REFERENCES}

1. World Health Organization. Sustainable health financing, universal coverage and social health insurance. Geneva: World Health Organization, 2005.

2. World Health Organization. The World Health Report 2010 - Health systems financing: the Path to universal coverage. Geneva: World Health Organisation, 2010.

3. Glassmann A, Giedion U. What will universal health coverage actually cover? . Cent Glob Dev 2013 http://www.cgdev.org/blog/ what-will-universal-health-coverage-actually-cover (accessed 3 Jun2014).

4. World Health Organization. The World Health Report 2008 Primary health care, now more than ever. Geneva: World Health Organization, 2008.

5. Giedion U, Tristao I, Escobar L, et al. Health benefit plans in Latin America: a Regional comparison: Inter-American Development Bank, 2014.

6. Abiiro GA, Torbica A, Kwalamasa K, et al. Eliciting community preferences for complementary micro health insurance: a discrete choice experiment in rural Malawi. Soc Sci Med 2014;120:160-8.

7. Biddle AK, DeVellis RF, Henderson G, et al. The health insurance puzzle: a new approach to assessing patient coverage preferences. J Community Health 1998;23:181-94.

8. Booske BC, Sainfort F, Hundt AS. Eliciting consumer preferences for health plans. Health Serv Res 1999;34:839-54.

9. Danis M, Biddle AK, Dorr Goold S. Insurance benefit preferences of the low-income uninsured. J Gen Intern Med 2002;17:125-33.

10. Danis M, Biddle AK, Goold SD. Enrollees choose priorities for Medicare. Gerontologist 2004;44:58-67.

11. Danis M, Binnendijk E, Vellakkal S, et al. Eliciting health insurance benefit choices of low income groups. Econ Polit Wkly 2007;11:3331-9.

12. Dong $H$, Mugisha F, Gbangou A, et al. The feasibility of community-based health insurance in Burkina Faso. Health Policy 2004;69:45-53.

13. Dror DM, Koren R, Ost A, et al. Health insurance benefit packages prioritized by low-income clients in India: three criteria to estimate effectiveness of choice. Soc Sci Med 2007;64:884-96.

14. Dror DM, Panda P, May C, et al. 'One for all and all for one': consensus-building within communities in rural India on their health microinsurance package. Risk Manag Healthc Policy 2014;7:139-53.

15. Kerssens JJ, Groenewegen PP. Consumer preferences in social health insurance. Eur J Health Econ 2005;6:8-15.

16. Leppert G. Social risk management strategies and health risk exposure: insights and evidence from Ghana and Malawi. Berlin: LIT, 2016.

17. Onwujekwe O, Onoka C, Uguru N, et al. Preferences for benefit packages for community-based health insurance: an exploratory study in Nigeria. BMC Health Serv Res 2010;10:162.

18. Taylor DH, Danis M, Zafar SY, et al. There is a mismatch between the medicare benefit package and the preferences of patients with cancer and their caregivers. J Clin Oncol 2014;32:3163-8.

19. Vroomen JM, Zweifel P. Preferences for health insurance and health status. Does it matter whether you are Dutch or German? Eur J Health Econ Health Econ Prev Care 2011;12:87-95. 
20. De Allegri M, Sanon M, Bridges J, et al. Understanding consumers' preferences and decision to enrol in community-based health insurance in rural West Africa. Health Policy 2006;76:58-71.

21. Panda P, Chakraborty A, Dror DM, et al. Enrolment in communitybased health insurance schemes in rural Bihar and Uttar Pradesh, India. Health Policy Plan 2014;29:960-74.

22. National Assembly of Vietnam. 2008.Law on health insurance No. 25/2008/QH12, Ha Noi, Viet Nam.

23. National Assembly of Vietnam. 2014. Revised law on health insuranceNo. 46/2014/QH13, Ha Noi, Viet Nam.

24. Ministry of Health, Health Partnership Group. Joint annual health review 2012: improving quality of medical services. Hanoi: Ministry of Health of Vietnam, 2012.

25. Ministry of Health, Health Partnership Group. Joint annual health review 2013: towards universal health coverage. Hanoi: Ministry of Health of Vietnam, 2013.

26. Ministry of Health, Health Partnership Group. Joint annual health review 2010: vietnam's health system on the threshold of five year plan 2011-2015. Hanoi: Ministry of Health of Vietnam, 2010.

27. Prime Minister of Vietnam. Decision 538 approving the project on the roadmap towards universal health coverage for the period of 2012 2015 and 2020.

28. Tran VT, Hoang TP, Mathauer I, et al. A health financing review of Viet Nam with a focus on social health insurance. WHO 2011. http:// www.who.int/health_financing/documents/cov-oasis_e_11-vietnam/ en/.(accessed 12 Jun 2014).

29. Neumann JV. Princeton NJ, ed. Theory of games and economic behavior. 60th anniversary. Woodstock: University Press Group Ltd, 2007.

30. Hurwicz L. The theory of economic behavior. Am Econ Rev 1945;35:909-25.

31. Dror DM, Jacquier C. Micro-insurance: extending Health Insurance to the excluded. Int Soc Secur Rev 1999;52:71-97.

32. Committee Provincial People's. 2012. Overview of Bac Giang. Bac Giang, Vietnam: Provincial People's Committee of Bac Giang. http:// www.bacgiang.gov.vn/tong-quan-bac-giang/.

33. Provincial Social Security of Bac Giang. 2011. Annual report on implementation progess of social health insurance in Bac Giang. Bac Giang, Vietnam: Provincial Social Security of Bac Giang.

34. Akunne AF, Bridges JF, Sanon M, et al. Comparison of individual and group valuation of health state scenarios across communities in West Africa. Appl Health Econ Health Policy 2006;5:261-8.
35. Weller SC, Romney AK. Systematic data collection. Newbury Park, Calif: SAGE Publications, 1988.

36. Anderson I. A first course in discrete mathematics. London: Springer, 2001.

37. Pett MA. Nonparametric statistics for health care research: statistics for small samples and unusual distributions. Thousand Oaks, California: SAGE Publications, 1997.

38. Ulin PR. Qualitative methods in public health: a field guide for applied research. 1st edn. San Francisco, CA: Jossey-Bass, 2005.

39. Mansfield E. Microeconomics: theory, applications. 6th ed. New York: Norton, 1988.

40. Arrow KJ. Uncertainty and the welfare economics of medical care. Am Econ Rev 1963;LIII:941-73.

41. Friedman B. Risk aversion and the consumer choice of Health Insurance option. Rev Econ Stat 1974;56:209-14.

42. Pauly MV. The demand for health insurance. Insights from theory and voluntary markets in less developed countries. Background paper presented at Wharton impact conference on voluntary health insurance in developing countries University of PennsylvaniaUSA2005. 15-16 March

43. Ministry of Health, Health Partnership Group. Joint annual health review 2015: strengthening primary health care at the grassroots towards universal health coverage. Hanoi: Ministry of Health of Vietnam, 2016

44. Ministry of Health, Health Partnership Group. Joint annual health review 2014: strengthening prevention and control of noncommunicable disease. Hanoi: Ministry of Health of Vietnam, 2014.

45. Ekman B, Liem NT, Duc HA, et al. Health insurance reform in Vietnam: a review of recent developments and future challenges. Health Policy Plan 2008;23:252-63.

46. Murray CJ, Frenk J. A framework for assessing the performance of health systems. Bull World Health Organ 2000;78:717-31.

47. World Health Organization. World Health Report 2000. Health Systems: improving Performance. Geneva: World Health Organisation, 2000.

48. Rosko MD, McKenna W. Modelling consumer choices of health plans: a comparison of two techniques. Soc Sci Med 1983;1982:421-9.

49. Samuelson W, Zeckhauser R. Status quo Bias in decision making. $J$ Risk Uncertain 1988;1:7-59. 